\title{
Diagnosis and Treatment of Colonic Diverticular Disease: Position Paper of the Romanian Society of Gastroenterology and Hepatology
}

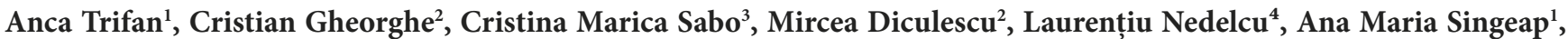 \\ Cătălin Sfarti ${ }^{1}$, Liana Gheorghe ${ }^{2}$, Ioan Sporea ${ }^{5}$, Marcel Tanțău ${ }^{6}$, Viorel Scripcariu ${ }^{1}$, Adrian Goldiș ${ }^{5}$, Dan Gheonea $^{7}$, Mircea $^{2}$
} Manuc $^{2}$, Carol Stanciu' ${ }^{1}$, Carmelo Scarpignato ${ }^{8}$, Dan L. Dumitrașcu ${ }^{3}$

1) Grigore T. Popa University

of Medicine and Pharmacy,

Dept. Gastroenterology, Iasi;

2) Center of Gastroenterology,

Fundeni Hospital, Carol

Davila University of Medicine

and Pharmacy Bucharest;

3) Iuliu Hatieganu University

of Medicine and Pharmacy, $2^{\text {nd }}$

Medical Dept. Cluj-Napoca;

4) Transilvania University,

Dept. Internal Medicine,

Brasov;

5) Victor Babeș University

of Medicine and Pharmacy,

Dept. Gastroenterology and

Hepatology, Timișoara

6) Iuliu Hatieganu University

of Medicine and Pharmacy,

Prof. Octavian Fodor Institute

of Gastroenterology and

Hepatology Cluj-Napoca;

7) University of Medicine

and Pharmacy, Dept.

Gastroenterology, Craiova,

Romania

8) Clinical Pharmacology and

Digestive Pathophysiology

Unit, Dept.Clinical and

Experimental Medicine,

University of Parma, Italy

Address for correspondence:

Dr. Cristina Marica Sabo

Iuliu Hatieganu University of

Medicine and Pharmacy

2nd Medical Department

Cluj-Napoca, Romania

Received: 18.10 .2018

Accepted: 26.11 .2018

*Society of Gastroenterology and Hepatology

\section{ABSTRACT}

Background \& Aims: Diverticular disease of the colon is a common clinical condition in developed countries, and is associated with significant (direct and indirect) economic burden. The aim of this Position Paper is to provide clinical guidance for appropriate definition, prevalence, risk factors, diagnosis, and treatment of colonic diverticular disease.

Methods: A working group of recognized experts established by the Board of the Romanian Society of Gastroenterology and Hepatology (RSGH) screened the literature and the available guidelines on colonic diverticular disease. Statements were formulated based on literature evidence. These statements were discussed within the working group and decision for each of them was taken by consensus.

Results: Thirty two statements were elaborated. The grade of recommendation, according to the level of evidence was established for each statement. Short comments with literature support accompany each statement.

Conclusion: This Position Paper represents a practical guide for clinicians dealing with patients affected by colonic diverticular disease.

Key words: colonic diverticulosis - diverticular disease - acute diverticulitis.

Abbreviations: AD: acute diverticulitis; CD: colonic diverticulosis; CEUS : contrast enhanced ultrasonography; CTC: computed tomography colonography; DCBE: double contrast barium enema; DD: diverticular disease; EL: evidence level; IBD: inflammatory bowel disease; IBS: irritable bowel syndrome; MRC: Magnetic resonance colonography; RG: recommendation grade; RSGH: Romanian Society of Gastroenterology and Hepatology; SCAD: segmental colitis associated with diverticulosis; SUDD: symptomatic uncomplicated diverticular disease; US: ultrasound

\section{INTRODUCTION}

Diverticular disease (DD) of the colon is a common disorder of the gastrointestinal tract, with highest prevalence in the Western industrialized countries (Western Europe, USA, Canada), increasing with the age, nowadays ranking as fifth most important gastrointestinal disease, in term of direct and indirect costs to society, which only in the US are estimated at 4 billion dollars per year $[1,2]$. Thanks to the increased life expectancy, the prevalence of DD is increasing not only in Western countries, but also in other geographical areas, previously considered as having low prevalence of such disorders (including Romania). Scientific societies from several countries have published national guidelines/consensus for the diagnosis and treatment of colonic DD; however, such guidelines/consensus are lacking in Romania.

The aim of this Position Paper was to provide clinical guidance recommendations for appropriate definition, prevalence, pathophysiology, diagnosis, complications, and treatment of colonic diverticulosis and diverticular disease.

\section{METHODOLOGY}

We selected a number of items considered to be relevant on epidemiology, pathogenesis, diagnosis and treatment of DD by a working group of recognized experts, on the basis of their scientific and practice expertise, including gastroenterologists, gastrointestinal endoscopists, radiologists and surgeons, selected by the Board of the RSGH. The working group carried out a systematic literature search for 
the years 1980-2017 regarding the epidemiology, risk factors, diagnosis and treatment of DD, using PubMed/Medline and issued statements, each with a recommendation grade (RG), according to the evidence level (EL), and using the Oxford Centre for Evidence-Based Medicine criteria [3]. The Grade of Recommendations, Assessment, Development and Evaluation (GRADE) system was used to grade the level of evidence [4]. The provisional statements circulated within the group and, after receiving feedback (comments, observations), the final version with 32 statements was submitted to the Board of RSGH for an open discussion and global consensus during a dedicated session at the National Congress of RSGH in May 2018. Electronic version of this Guidance, as well as periodically up-dated versions will be available on the site of RSGH (www.srgh.ro).

\section{STATEMENTS}

\section{Definition - Terminology - Classification}

Statement 1.1. (EL 1c-RG B). Diverticula are defined as herniations of the mucosa and submucosa through the muscular layer of colonic wall, while colonic diverticulosis (CD) refers to the presence of the asymptomatic colonic diverticula. Diverticular disease is defined as the presence of the diverticulosis with symptoms and/or complications. Symptomatic uncomplicated diverticular disease (SUDD) is a subtype of $\mathrm{DD}$, characterized by recurrent abdominal pain, bloating, altered bowel habits - symptoms, attributed to diverticula in the absence of colitis or diverticulitis (Fig.1) [5].

Comments: While $80 \%-85 \%$ of people with colonic diverticulosis remain asymptomatic, about 15\%-20\% will develop abdominal symptoms. Asymptomatic diverticulosis is most often an incidental finding in patients undergoing gastrointestinal examinations for other indication [6]. There may be an overlap between SUDD and irritable bowel syndrome (IBS), due to similar pathophysiologic mechanisms underlying both clinical conditions, including visceral hypersensitivity. Thus, it has been shown that SUDD patients had hyperalgesia in the sigmoid colon [7].

Statement 1.2. (EL 1 c - RG B). Diverticulitis is the inflammation of diverticula, and may be acute or chronic. Acute diverticulitis (AD) can be uncomplicated or complicated. Uncomplicated AD refers to diverticular inflammation without complications, while complicated AD indicates diverticulitis associated with complications (bleeding, abscess, perforation, peritonitis, fistula, obstruction). Segmental colitis associated with diverticulosis (SCAD) is a form of chronic diverticulitis with clinico-histological features resembling more like inflammatory bowel disease (IBD) than traditional diverticulitis. Chronic recurrent diverticulitis refers to recurrent bouts of overt diverticulitis rather than SCAD, occurring in patients with chronic diverticulitis (Fig. 1) [5].

Diverticula are classified into two groups: 1) true diverticula are those involving all layers of the colonic wall, are usually congenital and commonly located on the right colon; 2) false diverticula (pseudodiverticula) involve only mucosa and submucosa, are acquired, and usually located on the left colon.

\section{Epidemiology}

Statement 2.1. (EL $2 c-R G B)$. The prevalence of CD and DD is increasing in Western countries, as well as in countries previously considered as having low prevalence, mainly because of increased life-expectancy.

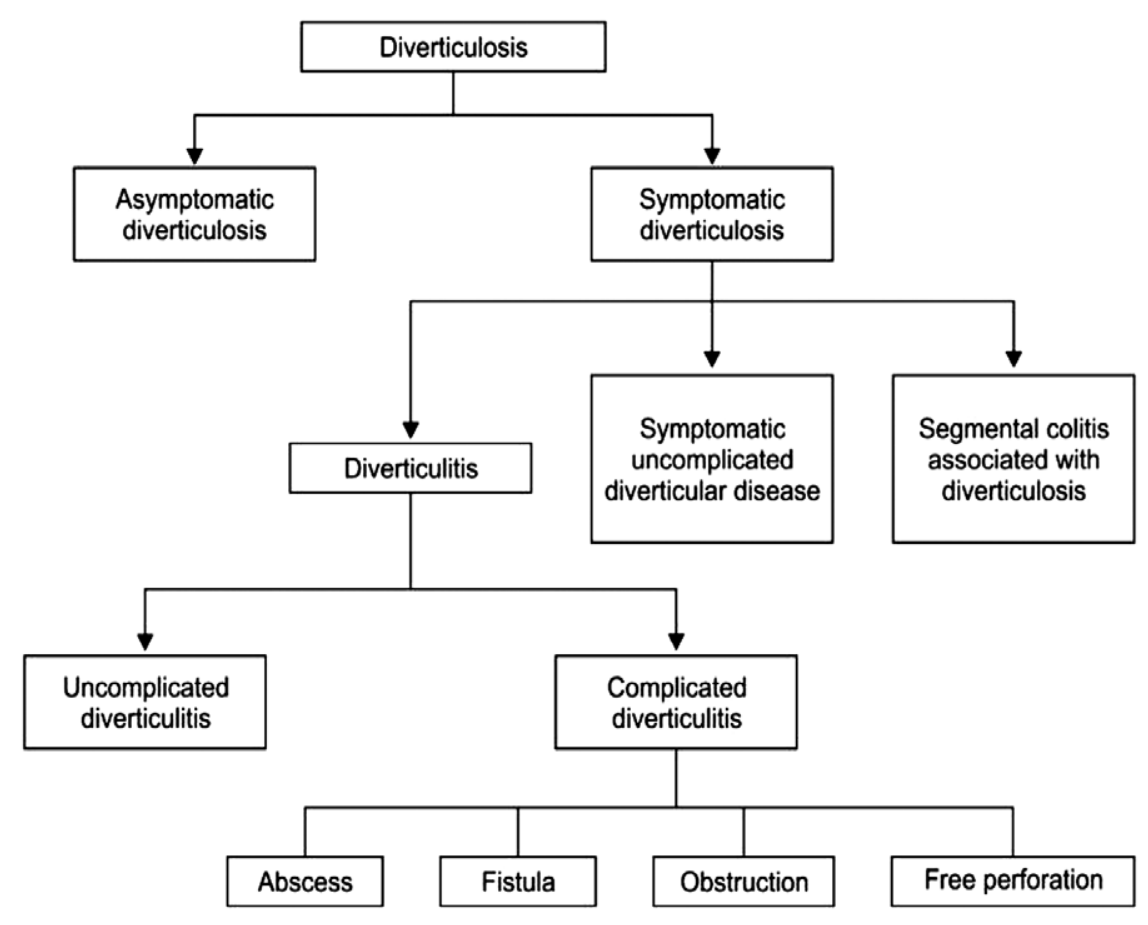

Fig. 1. Classification of diverticular disease [5]. 
Comments: Regarding epidemiology, CD has two characteristics: i) unequal geographic distribution (common in North America and Western Europe, rare in South America, Africa, Asia); ii) advanced age; the chance to develop diverticula during lifetime increases from less than $10 \%$ at age 40 to $30 \%$ by age 50 to $65 \%$ by age $80[8,9]$. The real prevalence of DD in Romania is unknown. What is known is that our elderly population is growing and we adopted for the last decades Western life-style. Therefore, a concomitant increase in prevalence of DD could be anticipated. Diverticulosis is the most frequent finding during colonoscopy, particularly in the elderly.

\section{Pathophysiology}

Statement 3.1. (EL $2 b-R G C)$. Low fiber diet is an important pathogenic factor in the development of diverticulosis and DD.

Comments: Painter and Burkitt were the firsts to report that a low fiber diet characteristic to Western Society is associated with high prevalence of $\mathrm{CD} / \mathrm{DD}$, while in geographical regions where fiber intake is high (Africa, Asia), these disorders are rare [10]. Several studies have supported the low fiber diet hypothesis reporting that prevalence of diverticulosis was lower in vegetarians than in non-vegetarians [11]. However, this hyphotesis has recently being challenged, with some studies reporting no association between low fiber diet and diverticulosis and actually showing that a high-fiber diet (and increased frequency of bowel movements) are associated with greater, rather than lower, prevalence of diverticulosis [12].

Statement 3.2. (EL $3-R G C)$. Changes in colonic motility play a potential pathogenic role in the development of the CD.

Comments: Several studies found an increase of both resting and stimulated colonic intraluminal pressure in patients with DD $[13,14]$. The presence of abnormal motility, segmentations of the colon by forming little bladders (with high pressure within every bladder favoring herniation of the mucosa), and of propulsive activity, as well as the abnormalities of neuromuscular function [15], all support the pathogenic role of deranged colonic motility in patients with diverticulosis.

Statement 3.3. (EL $3-R G C$ ). Changes in the colonic wall structure, particularly in connective tissue, play a key pathogenic role in the development of diverticulosis.

Comments: Age-related changes in the connective tissue of the colonic wall include an increase in collagen and elastin content, that cause increased colonic rigidity [16].

Statement 3.4. (EL $2 b-R G C$ ). Changes in gut microbiota play a potential role in the development of abdominal pain in SUDD.

Comments: In a descriptive, cross-sectional, pilot study Barbara and colleagues showed a depletion of microbiota members with antiinflammatory activity (including Clostridium cluster IV, Clostridium cluster IX, Fusobacterium and Lactobacillaceae) associated with mucosal macrophage infiltration ( $>70 \%$ increase in colonic macrophages) in patients with diverticular disease [17]. The lack of these bacteria from the intestinal microbiota have also been described in patients with intestinal inflammatory diseases and in those with IBS.

Statement 3.5. (EL $4-R G C$ ). In addition to diet low in fiber (statement 3.1.), other environmental factors such as smoking, obesity, alcohol consumption, physical inactivity, aspirin and other NSAIDs are associated with increased risk of CD and/or its complications.

Comments: The above associations, reported in several observational studies, are limited and often conflicting $[18,19]$.

Statement 3.6. (EL $2 \boldsymbol{b}-\boldsymbol{R} G \boldsymbol{B}$ ). Treatment with aspirin or NSAIDs is a significant risk factor for the development of symptomatic $\mathrm{DD}, \mathrm{AD}$ and its complications.

Comments. Many prospective studies reported that NSAID or aspirin users were significantly more likely to develop symptomatic uncomplicated or complicated DD (perforation, peritonitis, fistula, pericolic abscess), compared with nonusers [20].

Statement 3.7. (EL 3 - RG B). The use of opiate analgesics and corticosteroids may increase the risk of diverticular perforation.

Comments. There are few case control studies showing that the use of opioids and corticosteroids was significantly associated with perforated DD [20].

Statement 3.8. (EL $4-R G C$ ). Diverticular disease does not increase the risk for colorectal cancer.

Comments: A recent study including 41,037 patients with colon cancer concluded that the increased risk for cancer in DD reported in early studies was due to confounders [21].

\section{Diagnosis}

Statement 4.1. (EL $3 b-R G C$ ). Colonoscopy or CT colonography (CTC) are considered the first line diagnostic methods to confirm or rule out uncomplicated DD. Double contrast barium enema (DCBE) should be used only if CTC or colonoscopy is unavailable.

Comments: Both colonoscopy and double-contrast barium enema are contraindicated in the setting of suspected AD. An elective colonoscopy should be performed after 4-6 weeks from an episode of $\mathrm{AD}$, to exclude colon cancer in patients with thickening of the colon wall or stenosis, detected at initial CT (or transabdominal ultrasound). In comparison to colonoscopy and DCBE, CTC is less invasive, standardized, and has the ability to detect significant extra-colonic findings. Colonoscopy will generally be favored for cases with higher suspicion for an organic lesion or ongoing colonic inflammation, or where the need for histologic assessment is deemed more likely [22]. Recently, a standardized classification of colonic findings useful in DD called DICA (Diverticular Inflammation and Complications Assessment) has been introduced and validated as a tool to predict the future development of complications and the global outcome of the disease, suggesting when a medical therapy is indicated and likely to be effective. It consists of four endoscopic items (Fig. 2) [23]. In a retrospective study, this classification provided relevant information on the evolution of the disease, namely the risk of $\mathrm{AD}$ occurrence/recurrence and need for surgery [23]. A prospective study evaluating the predictive value of this classification is ongoing [24].

Statement 4.2. (EL $3-R G C)$. Colonoscopy is useful in the diagnosis and treatment of diverticular bleeding.

Comments: Diverticular bleeding is often self-limiting (70-90\%) [25]. Management algorithm for patients presenting with diverticular bleeding includes resuscitation followed by diagnostic evaluation. Colonoscopy, after preparation with polyethylene glycol-based solutions, is the recommended 


\begin{tabular}{|c|c|c|c|c|}
\hline Diverticula localization & \multicolumn{2}{|c|}{$\begin{array}{c}\text { Left } \\
\text { (score: } 2)\end{array}$} & \multicolumn{2}{|c|}{$\begin{array}{c}\text { Right } \\
\text { (score: } 1 \text { ) }\end{array}$} \\
\hline $\begin{array}{c}\text { No. of diverticula for each } \\
\text { localization }\end{array}$ & \multicolumn{2}{|c|}{$\begin{array}{c}\text { Grade I: } \leq 15 \text { diverticula } \\
\text { (score: } 0 \text { ) }\end{array}$} & \multicolumn{2}{|c|}{$\begin{array}{c}\text { Grade II: > } 15 \text { diverticula } \\
\text { (score: } 1 \text { ) }\end{array}$} \\
\hline Inflammation & $\begin{array}{l}\text { Absence } \\
\text { (score: } 0 \text { ) }\end{array}$ & $\begin{array}{l}\text { Edema/Hyperemia } \\
\text { (score: } 1 \text { ) }\end{array}$ & $\begin{array}{l}\text { Erosions } \\
\text { (score: } 2 \text { ) }\end{array}$ & $\begin{array}{c}\text { SCAD } \\
\text { (score: } 3 \text { ) }\end{array}$ \\
\hline \multicolumn{5}{|c|}{$\begin{array}{l}\text { If two different grades of severity are detected at the same time (for instance, some } \\
\text { diverticula with hyperemia and some other with erosions), the highest score should be } \\
\text { taken }\end{array}$} \\
\hline Complications & $\begin{array}{l}\text { Rigidity } \\
\text { (score: } 4 \text { ) }\end{array}$ & $\begin{array}{l}\text { Stenosis } \\
\text { (score: 4) }\end{array}$ & $\begin{array}{c}\text { Pus } \\
\text { (score:4) }\end{array}$ & $\begin{array}{l}\text { Bleeding } \\
\text { (score: 4) }\end{array}$ \\
\hline & & & & \\
\hline & & & & \\
\hline \multicolumn{2}{|c|}{ DICA Classification } & \multicolumn{3}{|c|}{ Global Score } \\
\hline \multicolumn{2}{|l|}{ DICA 1} & \multicolumn{3}{|c|}{ From 1 to 3 points } \\
\hline \multicolumn{2}{|l|}{ DICA 2} & \multicolumn{3}{|c|}{ From 4 to 7 points } \\
\hline \multicolumn{2}{|l|}{ DICA 3} & \multicolumn{3}{|c|}{$>7$ points } \\
\hline
\end{tabular}

Fig. 2. Standardized classification of endoscopic findings in patients with colonic diverticulosis: the DICA Score [23].

first-line investigation and helps in identifying the stigmata of recent hemorrhage and endoscopic management of the bleeding. Timing of colonoscopy after initial presentation varies among studies and ranges from 12 to $48 \mathrm{~h}$ [26]. Metallic clip placement or injections of adrenaline are used to obtain hemostasis, when the source of the bleeding is clearly identified. Surgery for diverticular bleeding is necessary when associated with hemodynamic instability and after failed endoscopic or angiographic interventions [27].

Statement 4.3. (EL $1 b-R G D)$. Abdominal ultrasound (US) and magnetic resonance colonoscopy (MRC) have no place in the first diagnostic approach of uncomplicated DD, while both techniques are useful for colonic examination in case of patients presenting with acute abdominal symptoms and clinical suspicion of AD.

Comments: Abdominal US is currently used as first investigation in patients with chronic abdominal complains and therefore, it may be useful as preliminary examination because has several advantages such as: noninvasive, quick use, easily repeatable, not expensive. In expert hands, US could identify diverticula as external hyperechoic pockets with shadows of the colonic wall. However, US cannot be recommended as a first line technique for the diagnosis of DD [28].

Statement 4.4. (EL $1 b-R G A$ ). Percutaneous ultrasound examination or contrast - enhanced CT are considered the first-line colonic examination in a patient suspected with acute complicated or uncomplicated diverticulitis. In addition to its diagnostic value, these methods offer a guide to therapeutic decisions.

Comments: CTC offers the most comprehensive examination of both complicated and uncomplicated forms of DD, particularly in case of perforation [29].

Statement 4.5. (EL 4 - RG D). Magnetic resonance colonoscopy (MRC) in the diagnosis of $\mathrm{AD}$ is an attractive method, although not well established.
Comments: MRC is rarely available in an emergency department [30].

\section{Treatment}

Medical treatment of uncomplicated DD

Statement 5.1. (EL $2 b-R G B$ ). There is no drug treatment for asymptomatic diverticulosis. However, there are some indications to increase intake in dietary fibers with the aim to reduce the risk of diverticular disease.

Comments. Several studies have reported that high fiber diets are associated with lower risk of DD. The German Society for Gastroenterology, Digestive and Metabolic Diseases/ General and Visceral Surgery, the Italian Society of Colon and Rectal Surgery (SICCR), the Polish Society of Gastroenterology and Surgery and the Italian Group on Diverticular Diseases (GRIMAD) recommend a high daily fiber intake, particularly insoluble fiber, for the sole purpose of preventing symptoms, but quality of evidence in support of this recommendation is rated as low [27, 31-33]. Crowe et al. examined associations between a vegetarian diet and the intake of fiber and the risk of DD in more than 47,000 individuals participating in the EPIC (European Prospective Investigation Into Cancer and Nutrition) - the Oxford study. They found that consuming a vegetarian diet with a high fiber intake was associated with a lower risk of hospital admission or death from DD [34]. This finding is reinforced by data from the prospective Million Women Study from the UK, which observed a reduced incidence of DD on a high-fiber diet. This finding did, however, depend on the specific sources of fibers, with the lowest risk resulting from fruit and cereal consumption [11]. In a separate study, Aldoori et al. found that the insoluble component of fiber (cellulose) was the most protective one [35].

Statement 5.2. ( $E L \mathbf{2} \boldsymbol{b}-\boldsymbol{R} \boldsymbol{G} \boldsymbol{B}$ ). The aims of treatment in SUDD should be the control of symptoms, prevention of complications and recurrences. 
Comments: SUDD usually improves with effective therapy. About $61 \%$ of patients who have had a previous attack of symptomatic DD and are not taking any medication become symptomatic within one year and about $4 \%$ eventually develop complications [36].

Statement 5.3. (EL $2 b-R G B$ ). The use of fiber supplementation alone in SUDD may improve clinical symptoms.

Comments: The efficacy of fiber supplements alone for symptoms relief, evaluated in several studies, has been controversial [37].

Statement 5.4. (EL2c - RG B). There is no rationale to exclude from the diet nut, corn or popcorn to prevent diverticular complications.

Comments: Conversely from previously thought, the recent evidence has shown that consumption of nut, corn or popcorn does not increase the risk of DD or diverticular complications and may actually protect from incident diverticulitis [38].

Statement 5.5. (EL $2 b-R G B)$. Non-absorbable antibiotic rifaximin, administered alone or in combination with fiber supplementation in SUDD showed a greater proportion of symptom-free patients compared to those who were taken fiber alone.

Comments: Recent studies have suggested the presence, at least in a subgroup of patients with diverticulosis, of a small intestinal bacterial overgrowth (SIBO), a condition allowing an excessive production of bowel gas through carbohydrate fermentation, with secondary development of abdominal pain, bloating and tenderness. Studies have shown the presence of altered microbiota in patients with DD, which correlates with mucosal immune activation and subsequent low-grade inflammation; thus, pharmacological approaches targeting enteric bacteria seem rational [39]. Poorly absorbed antimicrobials, unlike systemically available antibiotics, allow localized targeting of enteric pathogens and are associated with minimal risk of systemic toxicity or side effects. All the above findings represent a rationale for their use in DD [40, 41].

For more than 20 years, the use of rifaximin has been investigated in the treatment of SUDD. Rifaximin is an oral, non-systemic rifamycin analogue, with a broad spectrum, including action against Gram-positive and Gram-negative bacteria, aerobes, and anaerobes, and has a low risk of inducing bacterial resistance. The mechanisms by which rifaximin improves symptoms in SUDD are not fully understood.

A synergistic effect of rifaximin and a high-fiber diet have been suggested to reduce proliferation of gut microflora, with consequent decrease in bacterial hydrogen and methane production, and/or to increase fecal weight due to a decrease in bacterial degradation of fiber [42].

Rifaximin efficacy, both in the treatment of symptoms and prevention of complications has been recently summarized in two systematic reviews, one of which including a meta-analysis $[43,44]$. The meta-analysis [43] included four prospective randomized trials (of which only one was placebo-controlled, and double-blind) comprising 1,660 patients and found that $64 \%$ of patients treated with rifaximin plus standard fiber supplement were symptom free at 1-year follow-up, compared with $34.9 \%$ of patients treated with fiber alone. The pooled rate difference for symptom relief was $29.0 \%$ for rifaximin versus control (95\% CI: 24.5-33.6\%; $\mathrm{p}<0.0001$; number needed to treat $[\mathrm{NNT}]=3)$.

Statement 5.6. (EL $2 \boldsymbol{b}-\boldsymbol{R} G \boldsymbol{B}$ ). There is limited evidence that mesalazine (5 -ASA) alone provides symptom relief in DD or prevents attacks and/or recurrence of $\mathrm{AD}$.

Comments: It has been proposed that the chronic inflammation in DD is similar to that in inflammatory bowel disease (IBD), and therefore, 5-aminosalicylic acid (5-ASA) drugs commonly used in IBD have been studied in the management of SUDD. Mesalazine inhibits some key factors of the inflammatory cascade (cyclo-oxygenase, thromboxane-synthetase and PAF-synthetase), the production of interleukin-1 and free radicals, and has intrinsic antioxidant activity [45]. The efficacy of mesalazine in reducing symptoms of DD has been investigated in several uncontrolled studies and in two double-blind, placebo-controlled studies [46, 47], the results of which are summarized in a recent systematic review [48]. Despite some studies found an efficacy, they were of low methodological quality because of the lack of detailed description of patient history, symptoms assessment and inclusion as well as exclusion criteria.

Statement 5.7. (EL $4-R G C$ ). There is no clear evidence that probiotics are effective in reducing symptoms in DD.

Comments. The role of different probiotics (or probiotic mixtures) in preventing recurrence of SUDD has been investigated in small studies, summarized in a recent systematic review [49]. Many studies used probiotics in combination with poorly absorbed antibiotics or 5-ASA derivatives, finding them effective in treating SUDD patients $[50,51]$. However, the role of probiotics in DD is not yet established and guidelines do not currently recommend them.

\section{Acute diverticulitis}

Acute diverticulitis is the inflammation of one or more diverticula. The inflammation may be limited to the immediate vicinity of the diverticula (peridiverticulitis) or may be extended to the surrounding area and be associated with various complications (perforation, abscess, fistula, peritonitis). Among patients with diverticulosis, $10-25 \%$ are expected to develop $\mathrm{AD}$ in their lifetime [52], although a recent study suggested that this proportion might be much lower (i.e. $\leq 5 \%$ ) [53]. Acute diverticulitis can be uncomplicated or complicated. The majority of AD episodes are uncomplicated, with about $15 \%$ presenting complications as abscesses, fistulas, obstructions and perforations.

The Netherlands Society of Surgeons (NSS), the German Society for Gastroenterology, Digestive and Metabolic Diseases/General and Visceral Surgery (DGAV/DGVS) and the American Gastroenterological Association (AGA) acknowledge that the triad of left-sided lower abdominal pain, absence of vomiting and CRP (C-reactive protein) $>5$ $\mathrm{mg} / \mathrm{dl}$ has a high sensitivity for diverticulitis of up to $97 \%$, similar to a CT. However, they all demand an imaging method (transabdominal US or CT) to confirm the diagnosis [1,26, 5455]. The differential diagnosis of $\mathrm{AD}$ includes many conditions such as IBD, ischemic colitis or drug-induced colitis, acute appendicitis, gynecological diseases (anexitis, ovarian cyst, tubal pregnancy etc), urological diseases (ureteral colic, cystitis, pyelonefiritis etc), malignant diseases (colon cancer, ovarian 
tumor), diseases of the retroperitoneum (abcess, haematoma, aneurysm etc), all with overlapping signs and symptoms which can be challenging for the practitioner. The use of contrast enhanced ultrasonography (CEUS) is useful for the assessment of a peridiverticular collection.

\section{Treatment of AD}

Statement 6.1. (EL $3 b-R G C)$. Management of AD depends on severity (uncomplicated or complicated) of this condition.

Comments: The majority of AD episodes are uncomplicated, with about $15 \%$ presenting complications as abscesses, fistulas, obstructions and perforations. Patients with uncomplicated AD can be treated conservatively, often in the outpatient settings, whereas those with complicated disease need hospitalization and often surgery. A widely used classification to define AD severity and guide therapy is the modified Hinchey classification based on CT findings (Table I) [56]. The criteria for inpatient treatment include the presence of significant inflammation, intolerance to oral fluids, age over $80-85$ years, and presence of immunosuppression or comorbidities (diabetes, chronic renal failure, malignant hematological diseases, HIV infection, chemotherapy, steroid therapy, and transplant).

Statement 6.2. (EL $3 b-R G C$ ). In a mild uncomplicated $\mathrm{AD}$ (Hinchey 0 or Ia) and without severe comorbidities, age $<80$ years, and tolerant to oral fluids, outpatient treatment is effective and safe. Antibiotics should be used on a case-bycase basis.

Comments: Treatment recommendations in mild to moderate uncomplicated AD without severe concomitant diseases include clear liquid diet, analgesic, antipyretic and antispasmodic drugs. If opioid analgesics are required for pain control, meperidine is preferable to morphine, as this latter may lead to increased intracolonic pressure in the sigmoid [57]. Until recently, antibiotics have been the cornerstone of $\mathrm{AD}$ treatment, but recent studies found no evidence to the routine use of antibiotics. These findings suggest that the pathogenesis of $\mathrm{AD}$ is more inflammatory than infectious. Use of antibiotics in uncomplicated $\mathrm{AD}$ should be made individually [58].

Statement 6.3. (EL $3 \boldsymbol{b}-\boldsymbol{R} G \boldsymbol{C}$ ). Patients with severe AD, as well as those with mild to moderate $\mathrm{AD}$, but with at least one of the following features: intolerant to oral fluids, age over 80 years, with significant inflammation, presence of immunosuppression or comorbidities (chronic renal failure, diabetes), and those on chemotherapy or corticosteroid therapy, require always hospitalization, intravenous broadspectrum antibiotics, bowel rest, and parenteral fluids.
Comments. Antibiotics that are more often used in $\mathrm{AD}$ should cover anaerobic bacteria and include: ciprofloxacin (500 $\mathrm{mg}$ twice daily orally or $200 \mathrm{mg}$ twice daily i.v.) combined with metronidazole (250-500 mg three times daily orally or $500 \mathrm{mg}$ three times daily i.v.), penicillin derivatives such as ampicillin or piperacillin/tazobactam, or third-generation cephalosporin for 7-10 days. It should be emphasized, however, that the choice of antimicrobials is entirely empiric, since no trial has compared the efficacy of the different regimens mentioned above [39].

Statement 6.4 (EL $3 b-R G C$ ). The most appropriate treatment option for a diverticular phlegmon or abscess $<4 \mathrm{~cm}$ in diameter is antibiotic therapy alone, while abscesses $>4 \mathrm{~cm}$ in diameter need to be managed by percutaneous US-guided or CT-drainage; cases not amenable to percutaneous guided drainage should be treated surgically.

Comments: Several studies have reported that percutaneously guided drainage is effective and safe in patients with diverticular abscess $>4 \mathrm{~cm}$, but approximately one third of patients treated by this method still need surgery with segmental colonic resection [59]. US guided drainage is easy to be performed, is a quick and real-time method.

Statement 6.5 (EL $2 b-R G B)$. The indication for an elective surgery for recurrent $\mathrm{AD}$ should not be based on the number of previous episodes of $\mathrm{AD}$, but on a "case by case" basis.

Comments: Previous statements from most scientific societies agreed that a prophylactic colectomy (often sigmoidectomy) is indicated after two previous episodes of $\mathrm{AD}$ [60]. More recently, this myth has been dispelled and the indication for elective surgery is undertaken on "case by case" basis and not anymore based on the number of previous episodes of AD [61].

Statement 6.6. (EL $3 \boldsymbol{a}-\boldsymbol{R} G \mathbf{B})$. Elective resection surgery is recommended in patients with symptomatic complicated $\mathrm{AD}$ (e.g. stenosis) and should be performed in an inflammationfree interval.

Comments: Both prospective and retrospective studies comparing early and delayed surgical resection after an episode of $\mathrm{AD}$ showed that a late elective resection when remission of acute inflammation was obtained with antibiotic therapy led to better results $[62,63]$.

Statement 6.7. (EL $2 a-R G B$ ). Laparoscopic elective colonic resection for repetitive uncomplicated $\mathrm{AD}$ performed by trained surgeons offers some advantages over open colonic resection.

Comments: Randomized trials and a meta-analysis showed that laparoscopic elective colonic resection significantly

\begin{tabular}{|c|c|c|}
\hline 0 & Colonic wall thickening & Diverticula \pm colonic wall thickening \\
\hline Ia & Confined pericolic inflammation - phlegmon & $\begin{array}{l}\text { Colonic wall thickening with pericolic soft tissue } \\
\text { changes }\end{array}$ \\
\hline $\mathrm{Ib}$ & Confined pericolic abscess & Ia changes + pericolic or mesocolic abscess \\
\hline II & $\begin{array}{l}\text { Pelvic, distant intra-abdominal or retroperitoneal } \\
\text { abcess }\end{array}$ & $\begin{array}{l}\text { Ia changes }+ \text { distant abscess (generally deep in the } \\
\text { pelvis or interloop regions) }\end{array}$ \\
\hline III & Generalized purulent peritonitis & $\begin{array}{l}\text { Free gas associated with localized or generalized ascites } \\
\text { and possible peritoneal wall thickening }\end{array}$ \\
\hline IV & $\begin{array}{l}\text { Fecal peritonitis, Fistula colo-vesical/vaginal/enteric/ } \\
\text { cutaneous, Obstruction Large and/or small bowel }\end{array}$ & Same findings as III \\
\hline
\end{tabular}


reduced hospital stay and blood loss compared to open colonic resection $[64,65]$.

Statement 6.8. (EL $2 \boldsymbol{b}-\boldsymbol{R} G \boldsymbol{B}$ ). Resection with primary anastomosis with or without stoma or Hartman resection is the preferable surgical approach in most patients with an overt diverticular perforation and purulent peritonitis. Laparoscopic peritoneal lavage and drainage may be alternative to the respective procedure.

Comments: Hartmann resection is still recommended for surgical management of critically ill patients with diffuse peritonitis and those with multiple comorbidities [66].

Statement 6.9. (EL $4-R G C$ ). Urgent laparoscopic colon resection for perforated diverticulitis should be restricted to selected cases and to experienced laparoscopic centers with well-experienced laparoscopic surgeons.

Comments: Recently, a systematic review showed that laparoscopic sigmoidectomy for perforated diverticulitis is feasible [67]. However, this review included studies of low-quality evidence, performed in selected patients, and in experienced centers and therefore cannot be generalized to all centers.

\section{CONCLUSIONS}

These statements provide evidence-based clinical recommendations regarding appropriate definitions, epidemiology, pathophysiology, diagnosis and treatment of colonic diverticular disease. They are not mandatory rules and are neither infallible nor a substitute for clinical judgment. In addition, they do not apply to all clinical settings. Of course, periodic revisions of this Position Paper will be necessary as new knowledge becomes available.

Conflicts of interest: A.T., M.T. and C.Stanciu: speakers for Alfasigma; M.D. speaker Dr. Falk Pharma GmbH and Alfasigma; C.Scarpignato: member of the Advisory Board and of the Speakers' Bureau of Alfasigma; D. L. D.: speaker for Alfasigma and Biocodex. The other authors declare no conflicts of interest concerning this article.

Authors' contributions: A.T., M.D., C.Stanciu and D.L.D organized the production of this position paper, contributed to the literature search and participated to the writing of the paper. C.M.S searched literature and compiled the first draft of the manuscript. C.Scarpignato revised it critically for important intellectual content The others were experts contributing to the statements, making suggestions regarding the content of the manuscript. All the authors read and agreed the final version.

\section{REFERENCES}

1. Stollman N, Smalley W, Hirano I; AGA Institute Clinical Guidelines Committee. American Gastroenterological Association Institute Guideline on the Management of Acute Diverticulitis. Gastroenterology 2015;149:1944-1949. doi:10.1053/j.gastro.2015.10.003

2. Peery AF. Colonic diverticula and diverticular disease: 10 Facts Clinicians Should Know. N C Med J 2016;77:220-222. doi:10.18043/ ncm.77.3.220
3. Oxford Centre for Evidence-based Medicine - levels of evidence (March 2009). Available from: http://www.cebm.net/oxford-centre-evidencebased-medicine-levels-evidence-march-2009/

4. Atkins D, Best D, Briss PA, et al. Grading quality of evidence and strength of recommendations. BMJ 2004;328:1490. doi:10.1136/ bmj.328.7454.1490

5. Rezapour M, Ali S, Stollman N. Diverticular Disease: An Update on Pathogenesis and Management. Gut Liver 2018;12:125-132. doi:10.5009/gnl16552

6. Bhucket TP, Stollman NH. Diverticular disease of the colon. In: Feldman M, Friedman LS, Brandt LJ, eds. Sleisenger and Fordtran's gastrointestinal and liver disease: pathophysiology, diagnosis, management. Volume 2. 10th ed. Philadelphia: Elsevier, 2014:1-15.

7. Clemens CH, Samsom M, Roelofs J, van Berge Henegouwen GP Smout AJ. Colorectal visceral perception in diverticular disease. Gut 2004;53:717-722. doi:10.1136/gut.2003.018093

8. Everhart JE, Ruhl CE. Burden of digestive diseases in the United States part II: lower gastrointestinal diseases. Gastroenterology 2009;136:741754. doi:10.1053/j.gastro.2009.01.015

9. Commane DM, Arasaradnam RP, Mills S, Mathers JC, Bradburn M. Diet, ageing and genetic factors in the pathogenesis of diverticular disease. World J Gastroenterol 2009;15:2479-2488. doi:10.3748/wjg.15.2479

10. Painter NS, Burkitt DP. Diverticular disease of the colon: a deficiency disease of Western civilization. Br Med J 1971;2:450-454.

11. Crowe FL, Balkwill A, Cairns BJ, et al. Million women study collaborators. Source of dietary fiber and diverticular disease incidence: a prospective study of UK women. Gut 2014;63:1450-1456. doi:10.1136/ gutjnl-2013-304644

12. Peery AF, Barrett PR, Park D, et al. A high-fiber diet does not protect against asymptomatic diverticulosis. Gastroenterology 2012;142:266 272.e1. doi:10.1053/j.gastro.2011.10.035

13. Painter NS, Truelove SC, Ardran GM, Tuckey M. Segmentation and the localization of intraluminal pressures in the human colon, with special reference to the pathogenesis of colonic diverticula. Gastroenterology 1965;49:169-177.

14. Bassotti G, Battaglia E, Spinozzi F, Pelli MA, Tonini M. Twenty-four hour recordings of colonic motility in patients with diverticular disease: evidence for abnormal motility and propulsive activity. Dis Colon Rectum 2001;44:1814-1820. doi:10.1007/BF02234460

15. Bassotti G, Villanacci V. Colonic diverticular disease: abnormalities of neuromuscular function. Dig Dis 2012;30:24-28. doi:10.1159/000335702

16. Wess L, Eastwood MA, Wess TJ, Busuttil A, Miller A. Cross linking of collagen is increased in colonic diverticulosis. Gut 1995;37:91-94. doi:10.1136/gut.37.1.91

17. Barbara G, Scaioli E, Barbaro MR, et al. Gut microbiota, metabolome and immune signatures in patients with uncomplicated diverticular disease. Gut 2017;66:1252-1261. doi:10.1136/gutjnl-2016-312377

18. Spiller RC. Changing views on diverticular disease: impact of aging, obesity, diet, and microbiota. Neurogastroenterol Motil 2015;27:305312. doi:10.1111/nmo.12526

19. Aune D, Sen A, Leitzmann MF, Tonstad S, Norat T, Vatten LJ. Tobacco smoking and the risk of diverticular disease - a systematic review and meta-analysis of prospective studies. Colorectal Dis 2017;19:621-633. doi:10.1111/codi.13748

20. Piekarek K, Israelsson LA. Perforated colonic diverticular disease: the importance of NSAIDs, opioids, corticosteroids, and calcium channel blockers. Int J Colorectal Dis 2008;23:1193-1197. doi:10.1007/s00384008-0555-4 
21. Granlund J, Svensson T, Granath F, et al. Diverticular disease and the risk of colon cancer - a population-based case-control study. Aliment Pharmacol Ther 2011;34:675-681. doi:10.1111/j.13652036.2011.04782.x

22. Flor N, Maconi G, Cornalba G, Pickhardt PJ. The current role of radiologic and endoscopic imaging in the diagnosis and follow-up of colonic diverticular disease. AJR Am J Roentgenol 2016;207:15-24. doi:10.2214/AJR.16.16138

23. Tursi A, Brandimarte G, Di Mario F, et al. Predictive value of the Diverticular Inflammation and Complication Assessment (DICA) endoscopic classification on the outcome of diverticular disease of the colon: an international study. United European Gastroenterol J 2016;4:604-613. doi:10.1177/2050640615617636

24. Tursi A. A critical appraisal of advances in the diagnosis of diverticular disease. Expert Rev Gastroenterol Hepatol 2018;12:791-796. doi:10.10 80/17474124.2018.1487288

25. Poncet G, Heluwaert F, Voirin D, Bonaz B, Faucheron JL. Natural history of acute colonic diverticular bleeding: a prospective study in 133 consecutive patients. Aliment Pharmacol Ther 2010;32:466-471. doi:10.1111/j.1365-2036.2010.04362.x

26. Schreyer AG, Layer G; German Society of Digestive and Metabolic Diseases (DGVS) as well as the German Society of General and Visceral Surgery (DGAV) in collaboration with the German Radiology Society (DRG). S2k Guidelines for Diverticular Disease and Diverticulitis: Diagnosis, Classification, and Therapy for the Radiologist. Rofo 2015;187:676-684. doi:10.1055/s-0034-1399526

27. Cuomo R, Barbara G, Pace F, et al. Italian consensus conference for colonic diverticulosis and diverticular disease. United European Gastroenterol J 2014;2:413-442. doi:10.1177/2050640614547068

28. Hollerweger A, Macheiner P, Hübner E, Brunner W, Gritzmann N. Colonic diverticulosis: A comparison between sonography and endoscopy. Ultraschall Med 2002;23:41-46. doi:10.1055/s-2002-20075

29. Hainaux B, Agneessens E, Bertinotti R, et al. Accuracy of MDCT in predicting site of gastrointestinal tract perforation. AJR Am J Roentgenol 2006;187:1179-1183. doi:10.2214/AJR.05.1179

30. Heverhagen JT, Sitter H, Zielke A, Klose KJ. Prospective evaluation of the value of magnetic resonance imaging in suspected acute sigmoid diverticulitis. Dis Colon Rectum 2008;51:1810-1815. doi:10.1007/ s10350-008-9330-4

31. Kruis W, Germer CT, Leifeld L; German Society for Gastroenterology, Digestive and Metabolic Diseases and The German Society for General and Visceral Surgery. Diverticular disease: guidelines of the german society for gastroenterology, digestive and metabolic diseases and the german society for general and visceral surgery. Digestion 2014;90:190 207. doi:10.1159/000367625

32. Binda GA, Cuomo R, Laghi A, et al; Italian Society of Colon and Rectal Surgery. Practice parameters for the treatment of colonic diverticular disease: Italian Society of Colon and Rectal Surgery (SICCR) guidelines. Tech Coloproctol 2015;19:615-626. doi:10.1007/s10151-015-1370-x

33. Pietrzak A, Bartnik W, Szczepkowski M, et al. Polish interdisciplinary consensus on diagnostics and treatment of colonic diverticulosis (2015). Pol Przegl Chir 2015;87:203-220. doi:10.1515/pjs-2015-0045

34. Crowe FL, Appleby PN, Allen NE, Key TJ. Diet and risk of diverticular disease in Oxford cohort of European Prospective Investigation into Cancer and Nutrition (EPIC): prospective study of British vegetarians and non-vegetarians. BMJ 2011;343:d4131. doi:10.1136/bmj.d4131

35. Aldoori WH, Giovannucci EL, Rockett HR, Sampson L, Rimm EB, Willett WC. A prospective study of dietary fiber types and symptomatic diverticular disease in men. J Nutr 1998;128:714-719. doi:10.1093/ jn/128.4.714

36. Sarin S, Boulos PB. Long-term outcome of patients presenting with acute complications of disease. Ann R Coll Surg Engl 1994;76:117-120.

37. Ünlü C, Daniels L, Vrouenraets BC, Boermeester MA. A systematic review of high-fiber dietary therapy in diverticular disease. Int $\mathrm{J}$ Colorectal Dis 2012;27:419-427. doi:10.1007/s00384-011-1308-3

38. Strate LL, Liu YL, Syngal S, Aldoori WH, Giovannucci EL. Nut, corn, and popcorn consumption and the incidence of diverticular disease. JAMA 2008;300:907-914. doi:10.1001/jama.300.8.907

39. Scarpignato C, Barbara G, Lanas A, Strate LL. Management of colonic diverticular disease in the third millennium: Highlights from a symposium held during the United European Gastroenterology Week 2017. Therap Adv Gastroenterol 2018;11:1756284818771305. doi:10.1177/1756284818771305

40. Sopeña F, Lanas A. Management of colonic diverticular disease with poorly absorbed antibiotics and other therapies. Therap Adv Gastroenterol 2011;4:365-74. doi:10.1177/1756283X11412820

41. Bajaj JS, Barbara G, DuPont HL, Mearin F, Gasbarrini A, Tack J. New concepts on intestinal microbiota and the role of the non-absorbable antibiotics with special reference to rifaximin in digestive diseases. Dig Liver Dis 2018;50:741-749. doi:10.1016/j.dld.2018.04.020

42. D'Incà R, Pomerri F, Vettorato MG, et al. Interaction between rifaximin and dietary fiber in patients with diverticular disease. Aliment Pharmacol Ther 2007;25:771-779. doi:10.1111/j.13652036.2007.03266.x

43. Bianchi M, Festa V, Moretti A, et al. Meta-analysis: long-term therapy with rifaximin in the management of uncomplicated diverticular disease. Aliment Pharmacol Ther 2011;33:902-910. doi:10.1111/j.13652036.2011.04606.x

44. Maconi G, Barbara G, Bosetti C, Cuomo R, Annibale B. Treatment of diverticular disease of the colon and prevention of acute diverticulitis: a systematic review. Dis Colon Rectum 2011;54:1326-1338. doi:10.1097/ DCR.0b013e318223cb2b

45. MacDermott RP. Progress in understanding the mechanisms of action of 5-aminosalicylic acid. Am J Gastroenterol 2000;95:3343-3345. doi:10.1111/j.1572-0241.2000.03342.x

46. Kruis W, Meier E, Schumacher M, et al; German SAG-20 Study Group. Randomised clinical trial: mesalazine (Salofalk granules) for uncomplicated diverticular disease of the colon-a placebo-controlled study. Aliment Pharmacol Ther 2013;37:680-690. doi:10.1111/ apt. 12248

47. Tursi A, Brandimarte G, Elisei W, et al. Randomised clinical trial: mesalazine and/or probiotics in maintaining remission of symptomatic uncomplicated diverticular disease - a double-blind, randomised, placebo-controlled study. Aliment Pharmacol Ther 2013;38:741-751. doi:10.1111/apt.12463

48. Picchio M, Elisei W, Brandimarte G, et al. Mesalazine for the treatment of symptomatic uncomplicated diverticular disease of the colon and for primary prevention of diverticulitis: a systematic review of randomized clinical trials. J Clin Gastroenterol 2016;50 Suppl 1:S64-S69. doi:10.1097/MCG.0000000000000669

49. Lahner E, Bellisario C, Hassan C, Zullo A, Esposito G, Annibale B. Probiotics in the Treatment of Diverticular Disease. A Systematic Review. J Gastrointestin Liver Dis 2016;25:79-86. doi:10.15403/ jgld.2014.1121.251.srw

50. Tursi A, Brandimarte G, Giorgetti GM, Elisei W, Aiello F. Balsalazide and/or high-potency probiotic mixture (VSL\#3) in maintaining 
remission after attack of acute, uncomplicated diverticulitis of the colon Int J Colorectal Dis 2007;22:1103-1108. doi:10.1007/s00384-007-0299-6

51. Lamiki P, Tsuchiya J, Pathak S, et al. Probiotics in diverticular disease of the colon: an open label study. J Gastrointestin Liver Dis 2010;19:31-36.

52. Strate LL, Modi R, Cohen E, Spiegel BM. Diverticular disease as a chronic illness: evolving epidemiologic and clinical insights. Am J Gastroenterol 2012;107:1486-1493. doi:10.1038/ajg.2012.194

53. Shahedi K, Fuller G, Bolus R, et al. Long-term risk of acute diverticulitis among patients with incidental diverticulosis found during colonoscopy. Clin Gastroenterol Hepatol 2013;11:1609-1613. doi:10.1016/j. cgh.2013.06.020

54. Daniels L, Ünlü Ç, de Korte N, et al; Dutch Diverticular Disease (3D) Collaborative Study Group. Randomized clinical trial of observational versus antibiotic treatment for a first episode of CTproven uncomplicated acute diverticulitis. Br J Surg 2017;104:52-61. doi:10.1002/bjs.10309

55. Sartelli M, Catena F, Ansaloni L, et al. WSES Guidelines for the management of acute left sided colonic diverticulitis in the emergency setting. World J Emerg Surg 2016;11:37. doi:10.1186/s13017-016-0095-0

56. Klarenbeek BR, de Korte N, van der Peet DL, Cuesta MA. Review of current classifications for diverticular disease and a translation into clinical practice. Int J Colorectal Dis 2012;27:207-214. doi:10.1007/ s00384-011-1314-5

57. World Gastroenterology Organisation. WGO Practice Guidelines - Diverticular disease. 2007. Available from: http://www. worldgastroenterology.org/guidelines/global-guidelines/diverticulardisease

58. Tandon A, Fretwell VL, Nunes QM, Rooney PS. Antibiotics versus no antibiotics in the treatment of acute uncomplicated diverticulitis - a systematic review and meta-analysis. Colorectal Dis 2018;20:179-188. doi:10.1111/codi.14013
59. Singh B, May K, Coltart I, Moore NR, Cunningham C. The long-term results of percutaneous drainage of diverticular abscess. Ann R Coll Surg Engl 2008;90:297-301. doi:10.1308/003588408X285928

60. Parks TG. Natural history of diverticular disease of the colon. A review of 521 cases. Br Med J 1969;4:639-642.

61. Rafferty J, Shellito P, Hyman NH, Buie WD; Standards Committee of American Society of Colon and Rectal Surgeons. Practice parameters for sigmoid diverticulitis. Dis Colon Rectum 2006;49:939-944. doi:10.1007/ s10350-006-0578-2

62. Reissfelder C, Buhr HJ, Ritz JP. What is the optimal time of surgical intervention after an acute attack of sigmoid diverticulitis: early or late elective laparoscopic resection? Dis Colon Rectum 2006;49:1842-1848. doi:10.1007/s10350-006-0730-Z

63. Zingg U, Pasternak I, Guertler L, Dietrich M, Wohlwend KA, Metzger U. Early vs. delayed elective laparoscopic-assisted colectomy in sigmoid diverticulitis:timing of surgery in relation to the acute attack. Dis Colon Rectum 2007;50:1911-1917. doi:10.1007/s10350-007-9042-1

64. Gervaz P, Mugnier-Konrad B, Morel P, Huber O, Inan I. Laparoscopic versus open sigmoid resection for diverticulitis: long-term results of a prospective,randomized trial. Surg Endosc 2011;25:3373-3378. doi:10.1007/s00464-011-1728-8

65. Purkayastha S, Constantinides VA, Tekkis PP, et al. Laparoscopic vs. open surgery for diverticular disease: a meta-analysis of nonrandomized studies. Dis Colon Rectum 2006;49:446-463. doi:10.1007/s10350-0050316-1

66, Abbas S. Resection and primary anastomosis in acute complicated diverticulitis, a systematic review of the literature. Int J Colorectal Dis 2007;22:351-357. doi:10.1007/s00384-005-0059-4

67. Vennix S, Boersema GS, Buskens CJ, et al. Emergency Laparoscopic Sigmoidectomy for Perforated Diverticulitis with Generalised Peritonitis: A Systematic Review. Dig Surg 2016;33:1-7. doi:10.1159/000441150 